\title{
Formulation Optimization and Evaluation of Probiotic Lactobacillus sporogenes-Loaded Sodium Alginate with Carboxymethyl Cellulose Mucoadhesive Beads Using Design Expert Software
}

\author{
Himanshu K. Solanki', and Dushyant A. Shah ${ }^{3}$ \\ ${ }^{1}$ SSR College of Pharmacy, Saily-Silvassa Road, Saily, Silvassa, Dadra and Nagar Haveli 396230, India \\ ${ }^{2}$ Hemchandracharya North Gujarat University, Patan, Gujarat 384265, India \\ ${ }^{3}$ APMC College of Pharmaceutical Education and Research, Motipura, Himmatnagar, Sabarkantha, Gujarat 383001, India \\ Correspondence should be addressed to Himanshu K. Solanki; solanki_hims@yahoo.co.in
}

Received 24 August 2015; Revised 26 November 2015; Accepted 29 November 2015

Academic Editor: Franco P. Pedreschi

Copyright (C) 2016 H. K. Solanki and D. A. Shah. This is an open access article distributed under the Creative Commons Attribution License, which permits unrestricted use, distribution, and reproduction in any medium, provided the original work is properly cited.

The present study deals with the formulation optimization of sodium carboxymethyl cellulose-alginate mucoadhesive beads containing probiotic Lactobacillus sporogenes through ionotropic gelation using $3^{2}$ factorial design. The effect of sodium carboxymethyl cellulose-alginate concentration on the probiotic entrapment efficiency (PEE, \%), viability in simulated gastric fluid (log CFU/g), and mucoadhesion over $8 \mathrm{hr}(\%)$ was optimized. The optimized beads containing probiotic Lactobacillus sporogenes showed entrapment efficiency of $93.7 \pm 1.97 \%$, viability of probiotic in simulated gastric fluid (log CFU/g) of 9.34, mucoadhesion of $71.75 \pm 1.38 \%$, and mean diameter of $1.21 \pm 0.11 \mathrm{~mm}$. The beads were also characterized by SEM, FTIR, and XRD. The swelling and degradation of these beads were influenced by $\mathrm{pH}$ of the test medium. Finally, stability tests performed at room temperature $\left(25 \sim 28^{\circ} \mathrm{C}\right)$ highlighted a bacterial viability of about $91 \%$ and $86 \%$ after 1 and 2 months, respectively. The advantageous properties of probiotic Lactobacillus sporogenes-loaded mucoadhesive beads make them suitable for incorporation in functional food and/or pharmaceutical products.

\section{Introduction}

Probiotics are microorganisms that are introduced orally in the gastrointestinal tract (GIT) and are able to positively contribute to the activity of the intestinal microflora and to the health of its host. A variety of in vitro properties, including adhesion and resistance to $\mathrm{pH}$, have been investigated to determine the suitability of candidate bacterial strains as a probiotic [1]. Probiotics can provide beneficial effects on the human body by keeping the healthy gut microflora, inhibiting the growth of pathogenic bacteria, relieving constipation, stimulating the immune system, synthesizing vitamins and antimicrobial agents, and improving the absorption of calcium, when there are enough probiotics in colon [2].

In order to provide health benefits for probiotic bacteria [3] it has been recommended that they must be present at a minimum level of $10^{6} \mathrm{CFU} / \mathrm{g}$ of food product [4] or $10^{7} \mathrm{CFU} / \mathrm{g}$ at point of delivery or be eaten in sufficient amounts to yield a daily intake of $10^{8} \mathrm{CFU}[5]$.

It is believed that the efficiency of probiotic health benefits can be enhanced by coupling the application of probiotics with a selective prebiotic growth substance, thus favouring colonization of probiotics in the human gut [6]. Hence, a combined application of pro- and prebiotics, a concept referred to as synbiotics, $[7,8]$ also emerged in the field of probiotic microencapsulation.

The selection and optimization of a suitable microencapsulation process should be carried out such that the viability of encapsulated cells is maintained during both processing and storage. Thus, the selected method should be able to produce microspheres with the necessary physical/chemical attributes while causing minimal damage to cell integrity and 
viability and be easy to scale up with acceptable processing costs [9].

Many studies showed the potential of microencapsulation to improve probiotic survival during storage in food products or gastrointestinal transit as summarized in several reviews [10-12].

To our knowledge, nowadays no pharmaceutical studies were described for the encapsulation of probiotics associated with prebiotics BioEcolians ( $\alpha$-gluco-oligosaccharides) for therapeutic use while probiotics encapsulation is a process widely used in food applications in order to protect microorganisms against stomach acidity [12].

The most common encapsulation material is sodium alginate due to its simplicity, nontoxicity, biocompatibility, and low cost $[13,14]$. Alginate, the monovalent form of alginic acid belonging to a polysaccharide extracted from algae, consists of $\beta$-D-mannuronic and $\infty$-L-guluronic acids. The various amounts and sequential distribution of $\beta$-Dmannuronic and $\infty$-L-guluronic acids in chain can affect functional properties of alginate as a supporting material. Alginates undergo ionotropic gelation in aqueous solution in the presence of divalent cations like $\mathrm{Ca}^{2+}, \mathrm{Ba}^{2+}$, and so forth and trivalent cation like $\mathrm{Al}^{3+}$, due to an ionic interaction between the carboxylic acid groups located on the polymer backbone and these cations [15]. Alginates have mucoadhesive property, but the cross-linked alginates are usually fragile [16]. Therefore, to formulate various cross-linked alginate mucoadhesive microcapsules for controlled drug delivery, blending with mucoadhesive polymers is one of the most popular approaches. Again, blending with suitable polymers can improve the drug encapsulation and stability [17], which is found lower in alginate microcapsules, prepared by ionotropic gelation. Various mucoadhesive microcapsules of gliclazide using sodium alginate and mucoadhesive polymers such as sodium carboxymethyl cellulose, carbopol $934 \mathrm{P}$, and hydroxyl propyl methyl cellulose by ionotropic gelation was formulated by Prajapati et al. [18].

Nevertheless, it is found that no attempt has been taken to formulate probiotic Lactobacillus sporogenes-loaded alginatebased microcapsule or bead system using methyl cellulose as a mucoadhesive polymer.

The objectives of this research were first to optimize the conditions of microencapsulation of the probiotic strains $L$. sporogenes using the extrusion method to obtain beads and then to evaluate the survival of the encapsulated cells after the technological processing, under simulated gastrointestinal conditions and during storage at room temperature (24$28^{\circ} \mathrm{C}$ ) over a period of 2 months.

\section{Materials and Methods}

2.1. Materials. Lactobacillus sporogenes (ATCC 11748) were purchased from Unique Biotech Ltd., Hyderabad, India, and MRS agar and glucose yeast extract (GYE) agar medium, from Hi-media, Mumbai, India. Sodium alginate was procured from Chemdyes Pvt. Ltd, Rajkot, India, and sodium carboxy methyl cellulose (sodium CMC) was procured from Astron Chemicals, Ahmedabad, India. BioEcolians ( $\alpha$-glucooligosaccharides) were provided by Solabia group.
2.2. Microencapsulation Procedures. All glassware and solutions used in the protocols were sterilized at $121^{\circ} \mathrm{C}$ for $15 \mathrm{~min}$. The microencapsulation procedure employed in the present study used a slightly modified version of the extrusion technique [13]. In brief, 2.5 to $3.5 \%$ sodium alginate was mixed in distilled water containing $0.5-1 \%$ sodium carboxymethylcellulose; $2 \%$ BioEcolins; and $10^{10} \mathrm{CFU} / \mathrm{mL}$ of $L$. sporogenes. The cell suspension mixture and sodium alginate were injected into a $5 \% \mathrm{CaCl}_{2}$ solution using a sterile syringe. The droplets immediately formed gel spheres. The distance between the syringe and the $\mathrm{CaCl}_{2}$ solution was $3 \mathrm{~cm}$. The beads were then separated by filtration using Whatman filter paper, transferred to a sterile petri dish, and stored in a refrigerator until further use.

2.3. Experimental Design for Optimization. Factorial design is an experimental design technique, by which the factor involved and their relative importance can be assessed. In the present study, two-factor, three-level factorial design $\left(3^{2}\right)$ was employed for optimization with concentration of sodium alginate in \% $(A)$ and concentration of sodium CMC in $\%(B)$ as the prime selected independent variables, which were varied at three levels, low level $(-1)$, medium level (0), and high level $(+1)$. The entrapment efficiency (EE, \%), viability in SGF (log CFU), and mucoadhesion over $8 \mathrm{hr}(\%)$ were selected as responses. Design-Expert Version 9.0.4.1 software (Stat-Ease Inc., USA) was used for the generation and evaluation of the statistical experimental design. The matrix of the design including investigated responses, that is, entrapment efficiency (EE, \%), viability in SGF (log CFU), and mucoadhesion over $8 \mathrm{hr}(\%)$ are shown in Table 1 . The effects of independent variables upon investigated responses were modeled using following quadratic mathematical model

$$
Y=b_{0}+b_{1} A+b_{2} B+b_{3} A B+b_{4} A^{2}+b_{5} B^{2}
$$

where $Y$ is the response, $b_{0}$ is the intercept, and $b_{1}, b_{2}, b_{3}, b_{4}, b_{5}$ are regression coefficients. $A$ and $B$ are individual effects; $A^{2}$ and $B^{2}$ are quadratic effects; $A B$ is the interaction effect. One-way ANOVA was applied to estimate the significance $(p<0.05)$ of the model and individual response parameters. The surface response plots and contour plots were analyzed to reveal the effect of independent factors on the measured responses. Numerical optimization was performed using the desirability approach to develop optimized formulation. To check the validation of these generated mathematical models for optimization of the formulation, and overlay plot were analyzed.

2.4. Percentage Yield $(\% w / w)$. The percentage yield of prepared batches were calculated using the weight of final product after proper drying with respect to the initial total weight of probiotic and polymers used for preparation of beads. The percentage yield was calculated from the following formula:

$$
\text { Percentage Yield }=\frac{\text { Practical mass of beads }}{\text { Theoretical yield }} \times 100 \text {. }
$$




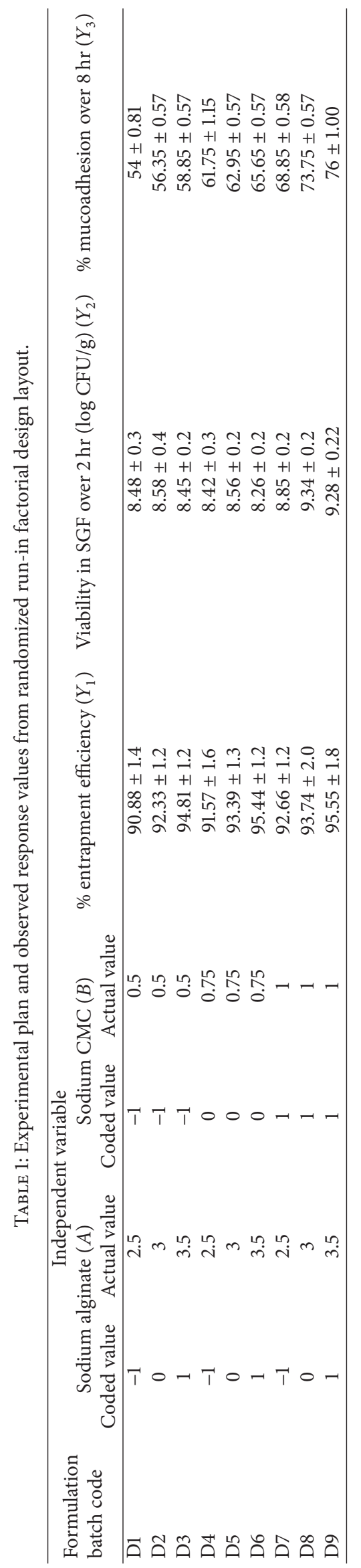


2.5. Probiotic Entrapment Efficiency (PEE). To determine Entrapment efficiency of beads, $100 \mathrm{mg}$ of dried beads were weighed and added to sterile conical flask containing simulated intestinal fluid ( $\mathrm{pH}$ 6.8). The added beads in conical flask were kept in orbital shaker at a period of $2 \mathrm{~h}$ for mechanical disintegration in the simulated intestinal fluid. $1.0 \mathrm{~mL}$ aliquot of the mixture was removed and adequate dilutions were made and subjected to a viable colony count (expressed in number of colony forming units (CFU)) of L. sporogenes count by pour plate method. The entrapment efficiency value was calculated using (3) and was reported in percent:

$$
\text { Entrapment efficiency }(\%)=\frac{\log _{10} N}{\log _{10} N_{0}} \times 100 \text {, }
$$

where $N$ is the number of colonies formed from the beads, and $N_{0}$ is the number of free cells added to the biopolymer mixture and number of colonies formed [19].

2.6. Determination of Bead Size. The particle sizes of the prepared beads were determined by measuring diameters of 20 dried beads at $\times 100$ magnifications using an optical microscope (Microtech, India) fitted with a calibrated micrometer scale. The mean diameters of beads were calculated and presented with standard deviations (Table 4).

2.7. Surface Morphology Analysis. The surface morphology of the formulated beads containing $L$. sporogenes was analyzed by SEM (JEOL, JSM-6360A). Beads were platinum coated by being mounted on a stub using double-sided adhesive tape and under vacuum in an auto fine coater (JEOL, JFC-1600) to make them electrically conductive and their morphology was examined by SEM.

\subsection{Fourier Transform-Infrared (FTIR) Spectroscopy. FTIR} spectra were recorded using $\mathrm{KBr}$ pellet in a FTIR spectrophotometer (Model: Bruker Alpha FTIR Spectrophotometer). Lactobacillus sporogenes, sodium alginate, sodium carboxy methylcellulose, calcium chloride, and Lactobacillus sporogenes-loaded microparticles were each separately finely grounded with $\mathrm{KBr}$. The pellet was placed in the sample holder. Spectral scanning was taken in the wavelength region between 4000 and $400 \mathrm{~cm}^{-1}$ at a resolution of $4 \mathrm{~cm}^{-1}$ with scan speed of $1 \mathrm{~cm} / \mathrm{s}$.

2.9. X-Ray Diffraction Study. X-ray powder diffractograms of Lactobacillus sporogenes, sodium alginate, and L. sporogenesloaded calcium alginate beads were recorded on an X-ray diffractometer (Instrument Details: Manufacturer: Panalytical Model: Xpert PRO MPD Anode: Copper K-alpha Wavelength: 1.5405 Angstorm Power: $45 \mathrm{KV}$ and $40 \mathrm{~mA}$ Detector: Xcelerator with Diffracted Beam). The samples were scanned between $2 \theta=3^{\circ}$ and $60^{\circ}$ at the scan rate of $4^{\circ} / \mathrm{min}$.

2.10. Determination of Viability of Encapsulated Probiotic in Simulated Gastric Fluid. For assessing the viability of probiotic in in vitro conditions (simulated gastric fluid),
$0.1 \mathrm{~g}$ of beads were taken from each formulation batch and introduced into $10 \mathrm{~mL}$ of simulated gastric fluid. For one hour of incubation interval in simulated gastric fluid for $2 \mathrm{~h}$, $1.0 \mathrm{~mL}$ aliquot was removed and serial dilutions were carried out using anaerobic solution. The serial dilutions $\left(10^{8}\right)$ were subjected to a viable colony count (expressed in number of colony forming units (CFU)) of $L$. Sporogenes by pour plate method on GYE agar media. The plates were incubated for $72 \mathrm{hrs}$ in the B.O.D incubator at $37^{\circ} \mathrm{C}$ and the colonies formed were counted by using colony counter.

2.11. Evaluation of Swelling Behavior. Swelling behavior evaluation of sodium alginate beads containing Lactobacillus sporogenes was studied by measuring the percentage swelling index of the formulated beads [20] (Figure 8). A known weight $(50 \mathrm{mg})$ of beads was placed in a conical flask containing $10 \mathrm{~mL}$ of simulated gastric fluid ( $\mathrm{pH}$ 1.2) for a period of time $(10,30,60,90$, and $120 \mathrm{~min})$ and during each time interval in simulated gastric fluid, the weight of the beads was determined after being blotted with a piece of filter paper to remove the excess water on the surface and was transferred to fresh medium (simulated gastric fluid) in order to continue to swell. After $120 \mathrm{~min}$, the beads were transferred to a conical flask containing $10 \mathrm{~mL}$ simulated intestinal fluid. The weight of the beads was determined for a period of time $(150,180$, and $210 \mathrm{~min}$ ). Fresh SIF was replaced at each time interval. The mass of dry beads was determined at time zero and the mass of wet beads was measured at each sampling point on a weighing balance (Precisa XR 205SM-DR) accurate to $\pm 0.001 \mathrm{~g}$. The percentage of swelling index was calculated using the following:

$$
\begin{aligned}
& \text { Swelling index (\%) } \\
& =\frac{\text { weight of beads after swelling - Dry wet of beads }}{\text { Dry wet of beads }} \\
& \quad \times 100 .
\end{aligned}
$$

2.12. In Vitro Wash-Off Test for Mucoadhesion. The mucoadhesive properties of sodium alginate beads containing Lactobacillus sporogenes were evaluated by ex vivo wash-off method [21]. Freshly excised pieces of goat intestinal mucosa $(2 \mathrm{~cm} \times$ $2 \mathrm{~cm}$ ) (collected from slaughterhouse) were mounted on glass slide $(7.5 \mathrm{~cm} \times 2.5 \mathrm{~cm})$ using thread. About 20 beads were spread onto the wet tissue specimen, and the prepared slide was hung onto a groove of disintegration test apparatus. The tissue specimen was given a regular up and down movement in a vessel containing $900 \mathrm{~mL}$ of simulated gastric fluid $(\mathrm{pH}$ 1.2) and simulated intestinal fluid $(\mathrm{pH}$ 6.8), separately, at $37 \pm 0.5^{\circ} \mathrm{C}$. After regular time intervals, the machine was stopped and the number of beads still adhering to the tissue was counted. The mucoadhesion value was calculated using (5) and was reported in percent:

Mucoadhsion (\%)

$=\frac{\text { No. of microbeads applied }- \text { No. of microbeads leached out }}{(\text {. }}$

$$
\text { No. of microbeads applied }
$$


2.13. Stability Studies of Free and Encapsulated L. sporogenes. The stability studies were conducted on the free and encapsulated $L$. sporogenes-loaded selected optimized formulation F-O at room temperature $\left(24-28^{\circ} \mathrm{C}\right)$. The stability studies were done at the intervals of 0,30 , and 60 days. The parameters studied were entrapment efficiency and viability of L. sporogenes.

2.14. Statistical Analysis. Statistical optimization was performed using Design-Expert Version 9.0.4.1 software (StatEase Inc., USA). All measured data are expressed as mean \pm standard deviation (S.D.) of replicated determinations. Data were subjected to one-way analysis of variance (ANOVA). Statistical significance was set at $p \leq 0.05$.

\section{Result and Discussion}

3.1. Optimization. In the development of pharmaceutical dosage forms, an important and crucial issue is to search an optimal formula for designing a product of desired quality by minimum trials within a short period [22]. Optimization by means of computer-aided statistical experimental design methodologies has been successfully applied in the literature for the development of various pharmaceutical dosage forms $[23,24]$. The statistical optimization technique encompasses designing a set of experiment that will reliably measure the response variables, fitting mathematical models to the data, conducting appropriate statistical tests to select best possible model, and determining the values of independent formulation variables to produce optimum response. Among various statistical design, factorial design is one of the popular experimental designs that have been employed in the formulation optimization $[25,26]$.

Optimization of the concentrations of the formulation factors was performed to obtain probiotic microparticles with enhanced viability of $L$. sporogenes and adequate release profile in different regions of the gastrointestinal tract. Although several responses were monitored to select the optimal values of the formulation factors, the main concern was given to the viability of $L$. sporogenes in simulated gastric fluid. This implication is accounted on the fact that the probiotics must first survive the deleterious effect of the gastric $\mathrm{pH}$ in order to reach the intestine where the bioadhesive properties of the delivery system are among the key factors for achieving prolonged residence time and effective colonization of the probiotic.

For the $3^{2}$ factorial designs, 9 trial formulations were suggested by Design-Expert 9.0.4 software (Stat-Ease Inc., USA) for two independent variables: $\%$ amount of sodium alginate $(A)$ and $\%$ amount of Sodium CMC $(B)$, which were varied at three levels: low level $(-1)$, medium level $(0)$, and high level $(+1)$. The $\%$ entrapment efficiency $\left(Y_{1}\right), \log$ CFU viability in SGF $\left(Y_{2}\right)$, and \% mucoadhesion over 8 hours $\left(Y_{3}\right)$ were evaluated as dependent variables (responses) in the current investigation. According to this trial plan, alginate sodium CMC beads containing L. sporogenes were prepared through ionotropic gelation. Overview of matrix of the design including investigated responses is presented in Table 1.
The values of investigated responses measured for all trial formulations were fitted in the $3^{2}$ factorial designs to get model equations for responses analyzed in this investigation. These models were evaluated statistically by applying oneway ANOVA $(p<0.05)$. The result of the ANOVA is shown in Table 2.

The model equations relating various measured responses became

$$
\begin{aligned}
& \text { Entrapment Efficiency }(\%) Y_{1} \\
& \quad=80.71944+3.56333 \times A+2.62000 \times B, \\
& \text { Viability in SGF }\left(\log _{10} \mathrm{CFU}\right) Y_{2} \\
& =+5.77658+4.28986 \times A-11.38256 \times B \\
& \quad+0.92991 \times A B-0.81776 \times A^{2}+6.59816 \times B^{2}, \\
& \text { Mucoadhesion }(\%) Y_{3} \\
& =+23.63889+5.30000 \times A+32.93333 \times B .
\end{aligned}
$$

It can be noted that all coefficients of these above three mathematical models had statistical significance $(p<0.05)$. The influences of main effects (factors) on responses investigated were further elucidated by response surface methodology. Response surface methodology has been reported as an effective tool for optimization of a dosage form to investigate the combined effect (interaction) of investigated factors on the desired responses [25-27]. In the response surface methodology, the three-dimensional response surface graph is very useful in learning about the main and interaction effects of the factors, whereas two-dimensional contour plot gives a visual representation of the response [26].

\subsection{Effect of Formulation Variable on \% Entrapment Efficiency} $\left(Y_{1}\right)$. The three-dimensional response surface plot and corresponding two-dimensional contour plot relating entrapment efficiency are presented in Figures 1(a) and 1(b), respectively. The $R^{2}$ (0.9707) was high indicating the adequate fitting of the linear model. The polynomial equations can also be used to draw conclusions considering the magnitude of coefficient and the mathematical sign it carries, that is, positive. The $\%$ entrapment efficiency of all the batches was within 90.88 to 95.55\% (Table 1). It was observed that PEE (\%) of these beads containing $L$. sporogenes was increased with the increment of sodium alginate and sodium CMC amount in the polymer blend. The increased PEE (\%) with the increasing amount of sodium alginate and sodium CMC in these beads may be due to the increase in viscosity of the polymer solution with the increasing amount of polymer addition, so that it might have prevented drug leaching to the cross-linking solution. In addition, the increasing amount of sodium alginate and sodium CMC in polymer-blend might have elevated the cross-linking by $\mathrm{CaCl}_{2}$ through availing more numbers of sites for ionic cross-linking.

Among the nine batches D9 showed highest \% probiotic entrapment efficiency, and this may be due to a high level of sodium alginate and sodium $\mathrm{CMC}$ which allows the probiotic 
TABLE 2: Summary of ANOVA for the response parameters in $3^{2}$ factorial designs.

\begin{tabular}{|c|c|c|c|c|c|c|}
\hline Source & Sum of squares & df & Mean square & $F$ value & $\begin{array}{l}p \text { value } \\
\text { Prob. }>F\end{array}$ & Significance \\
\hline \multicolumn{7}{|c|}{ For entrapment efficiency (\%) } \\
\hline Model & 21.62 & 2 & 10.81 & 99.23 & $<0.0001$ & Significant \\
\hline$A$ & 19.05 & 1 & 19.05 & 174.83 & $<0.0001$ & \\
\hline$B$ & 2.57 & 1 & 2.57 & 23.63 & 0.0028 & \\
\hline Residual & 0.65 & 6 & 0.11 & & & \\
\hline Cor. total & 22.27 & 8 & & & & \\
\hline \multicolumn{7}{|c|}{ For viability in SGF $\left(\log _{10}\right.$ CFU) } \\
\hline Model & 1.13 & 5 & 0.23 & 12.84 & 0.03 & Significant \\
\hline$A$ & 0.06 & 1 & 0.06 & 3.53 & 0.16 & \\
\hline$B$ & 0.30 & 1 & 0.30 & 17.00 & 0.03 & \\
\hline$A B$ & 0.05 & 1 & 0.05 & 3.08 & 0.18 & \\
\hline$A^{2}$ & 0.08 & 1 & 0.09 & 4.77 & 0.12 & \\
\hline$B^{2}$ & 0.34 & 1 & 0.34 & 19.40 & 0.02 & \\
\hline Residual & 0.05 & 3 & 0.018 & & & \\
\hline Cor. total & 1.18 & 8 & & & & \\
\hline \multicolumn{7}{|c|}{ For mucoadhesion (\%) } \\
\hline Model & 448.86 & 2 & 224.43 & 188.54 & $<0.0001$ & Significant \\
\hline$A$ & 42.14 & 1 & 42.14 & 35.40 & 0.0010 & \\
\hline$B$ & 406.73 & 1 & 406.73 & 341.68 & $<0.001$ & \\
\hline Residual & 7.14 & 6 & 1.19 & & & \\
\hline Cor. total & 456.03 & 8 & & & & \\
\hline
\end{tabular}
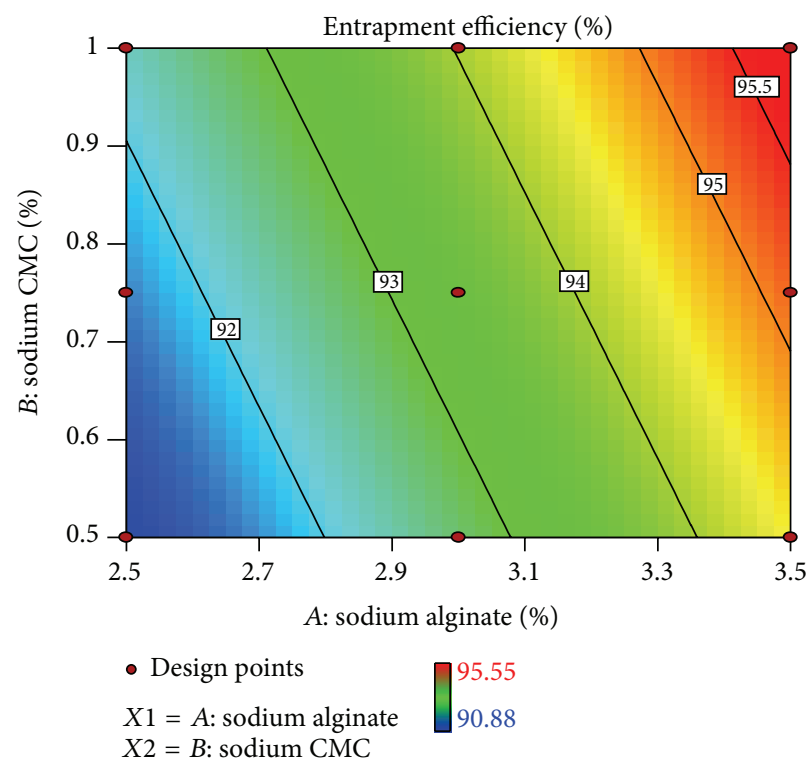

(a)

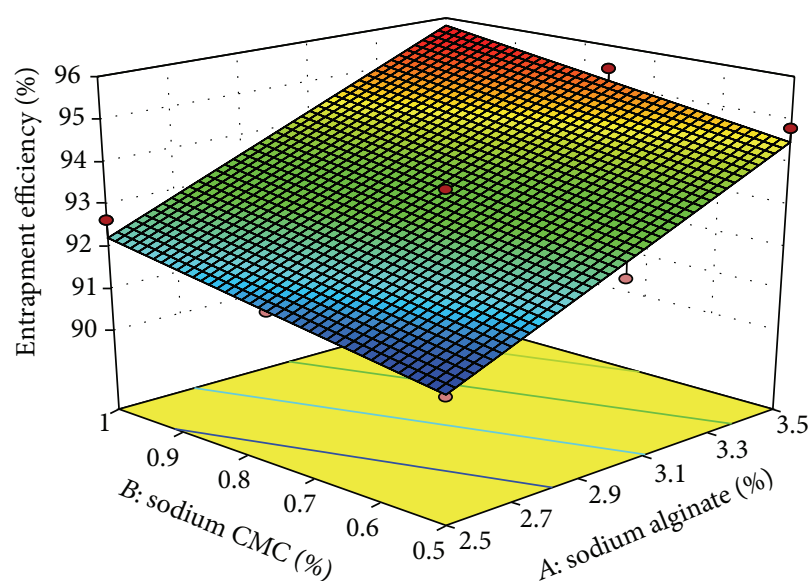

- Design points above predicted value - Design points below predicted value $X 1=A$ : sodium alginate $X 2=B$ : sodium CMC

(b)

FIGURE 1: Effect of formulation variable on \% entrapment efficiency presented by (a) contour plots and (b) response surface plots.

to get entrapped more as compared to formulation containing a low level of sodium alginate and sodium CMC (Figure 5).

3.3. Effect of Formulation Variables on Log CFU Viability of L. sporogenes in $S G F\left(Y_{2}\right)$. Response surface plot and corresponding two-dimensional contour plot relating viability in SGF are presented in Figures 2(a) and 2(b), respectively.

The $R^{2}(0.9554)$ was high indicating the adequate fitting of the quadratic model. The polynomial equations can also be used to draw conclusions considering the magnitude of coefficient and the mathematical sign it carries, that is, positive or negative. According to the values of regression coefficients, $A, B$ (Table 2 ), the viability of $L$. sporogenes in microparticles obtained was mostly affected by the sodium alginate $(A)$, while the sodium CMC $(B)$ concentration had the lowest influence on this response. The best response for the probiotic viability was obtained at sodium CMC concentration of $1 \% \mathrm{~W} / \mathrm{V}$ in the concentration range of alginate $3 \%$ 


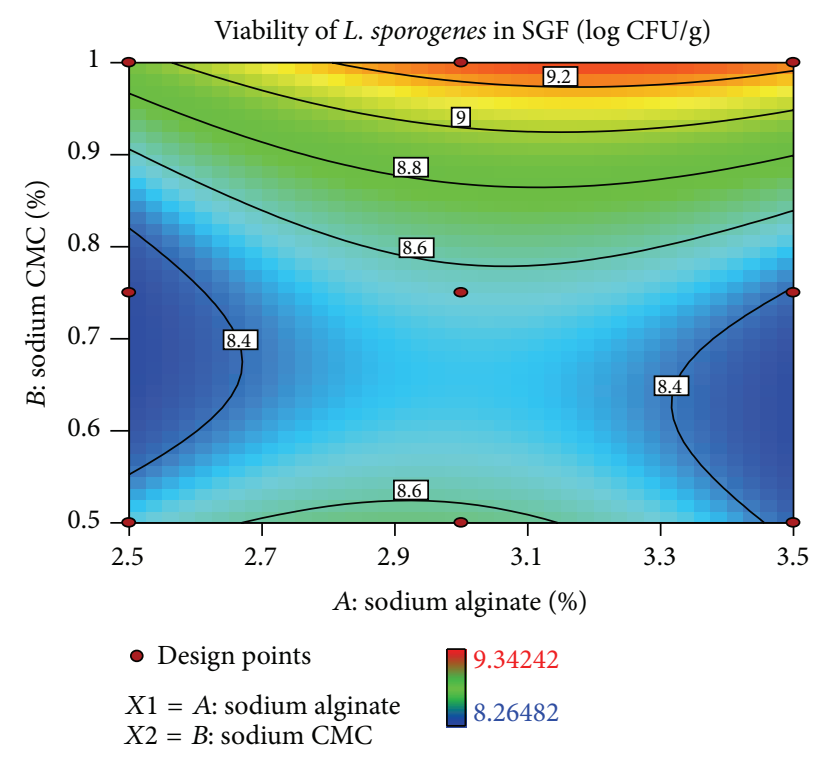

(a)

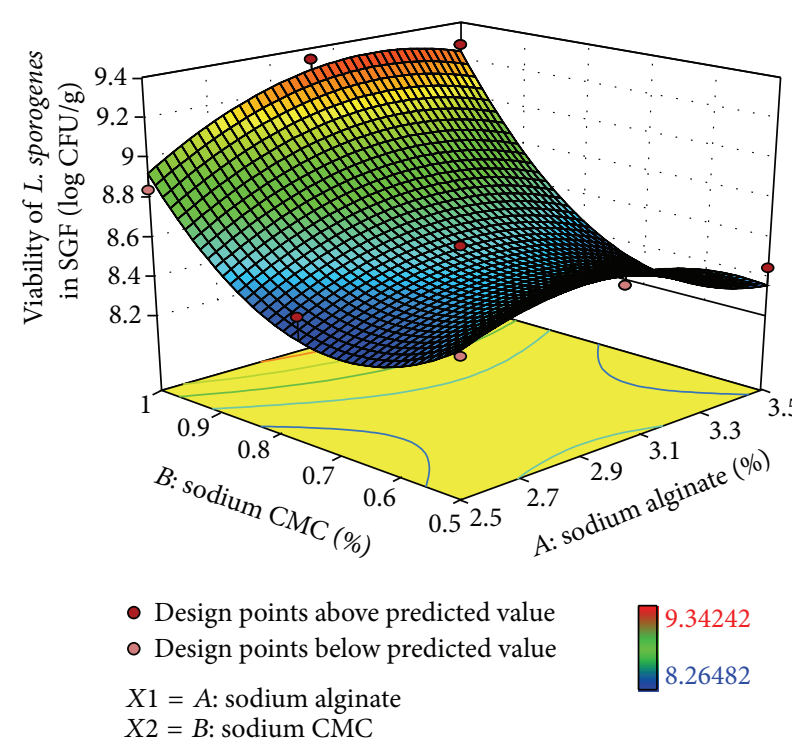

(b)

FIGURE 2: Effect of formulation variable on viability in SGF (log CFU) presented by (a) contour plots and (b) response surface plots.

$\mathrm{W} / \mathrm{V}$ and $\mathrm{CaCl}_{2}$ 5\% W/V, however, with no significant effect on the probiotic viability when increased sodium alginate concentration up to 3.5 was used. The viability of $L$. sporogenes of all batches was within 8.48 to $9.34 \log$ CFU (Table 1).

In fact, microencapsulated L. sporogenes showed that more than $10^{8} \mathrm{CFU} / \mathrm{mL}$ L. sporogenes capsules survived after $120 \mathrm{~min}$ and were resistant to simulated gastric conditions. The results showed that microencapsulation in alginate significantly $(p<0.05)$ improved the survival rate of $L$. sporogenes.

Chandramouli et al. (2004) and Iyer and Kailasapathy (2005) have shown that only the microencapsulated probiotics were able to maintain viability in gastrointestinal conditions $[28,29]$. Microencapsulation of probiotics in alginate beads has previously been tested for improving viability of probiotic bacteria in simulated gastric conditions [30] although some authors have reported the effect of alginate encapsulation on survival of lactic acid bacteria in simulated gastrointestinal conditions [31-33].

3.4. Effect of Formulation Variables on Mucoadhesion $\left(Y_{3}\right)$. The $R^{2}(0.9990)$ was high indicating the adequate fitting of the linear model.

Response surface plot and corresponding two-dimensional contour plot relating mucoadhesion are presented in Figures 3(a) and 3(b), respectively.

The mucoadhesion was significantly $(p<0.05)$ increased as the concentration of sodium alginate and sodium CMC increased over the range of 2.5 to $3.5 \%$ and 0.5 to $1.0 \%$, respectively. Formulation D9 (containing concentration of sodium alginate $3.5 \%$ and sodium CMC $1 \%$ ) exhibited maximum mucoadhesive strength. The result also showed that both sodium alginate and sodium CMC significantly increased the viscosity as well as the mucoadhesive property. Sodium
CMC has an abundance of hydroxyl and ether groups along their length, which are responsible for the mucoadhesive properties. Increasing the concentration of the sodium CMC in the formulation increased the bonds forming groups, thus increasing the mucoadhesive force of the formulations. Mucoadhesion behavior of alginate was due to the low surface tension $(31.5 \mathrm{mN} / \mathrm{m})$ of the alginate, which is lower than the critical surface tension of the mucin $(38 \mathrm{mN} / \mathrm{m})$, resulting in good spreading and adhesion.

The three-dimensional response surface graph relating to mucoadhesion (Figure 3 ) indicates the increase in mucoadhesion observed with increasing amount of sodium CMC $(A)$ and amount of sodium alginate $(B)$.

The influences of main effects (factors) on responses (here, \% encapsulation efficiency, viability in SGF, and \% mucoadhesion over 8 hours) were further elucidated by response surface methodology. Response surface methodology is a widely proficient approach in the development and optimization of drug delivery devices. The purpose of the response surface methodology is to understand as fully as possible the effect of factors and their levels in a model, over the whole of the experimental domain and to predict the response inside the domain. Moreover, it can be used for optimizing a formula (i.e., maximizing one or more of the responses, keeping the formulation variable setting within a satisfactory range), carrying out simulations with the model equations and plotting the responses. The three-dimensional response surface graph is very useful in learning about the main and interaction effects of the independent variables (factors), whereas two-dimensional contour plot gives a visual representation of values of the response. The threedimensional response surface plots and corresponding contour plots were presented to estimate the effects of the independent variables (factors) on each response investigated. 


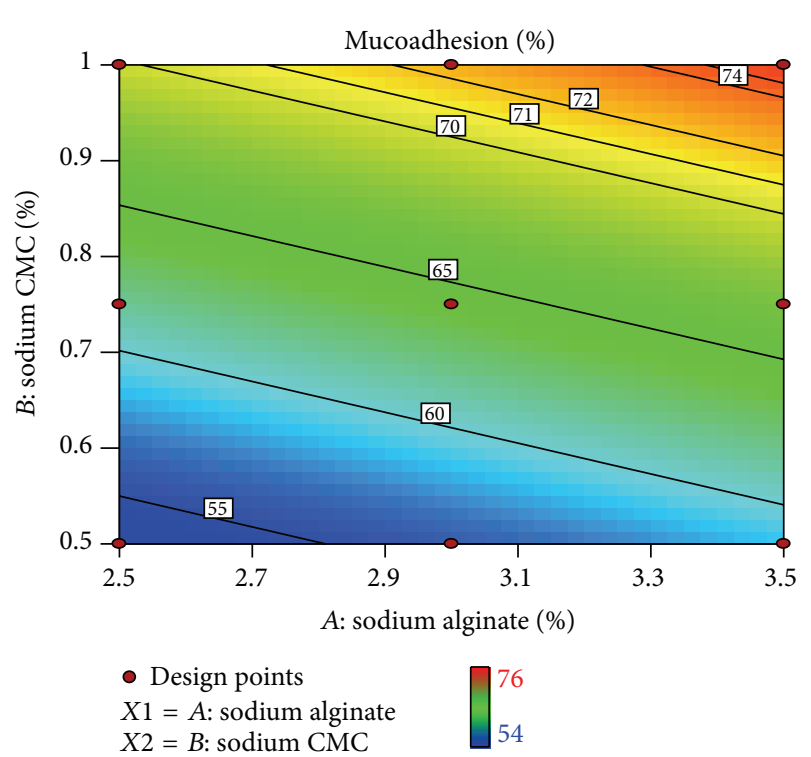

(a)

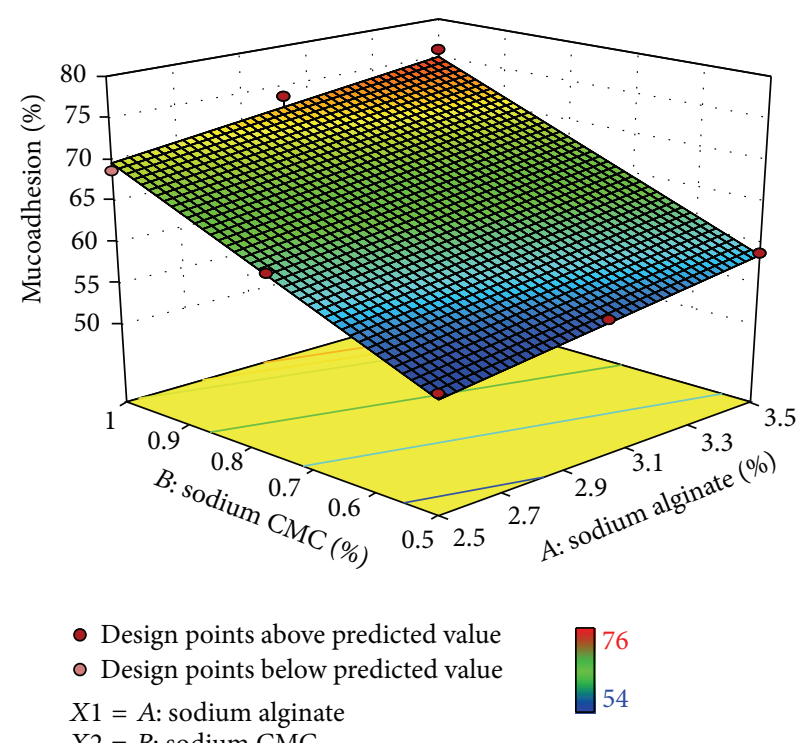

(b)

FIGURE 3: Effect of formulation variable on mucoadhesion (\%) presented by (a) contour plots and (b) response surface plots.

A numerical optimization technique using the desirability approach was employed to develop new formulations with desired response (optimum quality). The desirable ranges of the undependable variables (factors) were restricted to $2.5 \leq$ $A \leq 3.5 \%$ and $0.5 \leq B \leq 1.0 \%$, whereas the desirable ranges of responses were restricted to $90 \leq Y_{1} \leq 95 \%, 8.8 \leq Y_{2} \leq 9.3$ $\log \mathrm{CFU}$, and $70 \leq Y_{3} \leq 80 \%$. The optimal values of responses were obtained by numerical analysis using the Design-Expert 9.0.4.1 software and one of them was selected based on the criterion of desirability. In order to evaluate the optimization capability of the mathematical models generated according to the results of full $3^{2}$ factorial design, optimized sodium alginate-sodium CMC mucoadhesive beads containing $L$. Sporogenes were prepared by ionotropic gelation technique using these optimal process variable settings proposed by the design (Table 3 ). The selected optimal process variable setting used for the formulation of optimized formulation was $A=$ $3.27 \%$ and $B=1.00 \%$. Optimized sodium alginate-sodium CMC mucoadhesive beads containing L. Sporogenes (F-O) were evaluated $Y_{1}, Y_{2}$ and $Y_{3}$.

The optimized mucoadhesive beads containing L. sporogenes $(\mathrm{F}-\mathrm{O})$ showed $Y_{1}$ of $93.7 \pm 1.97 \%, Y_{2}$ of 9.34 , and $Y_{3}$ of $71.75 \pm 1.38 \%$ with small percentage error values $(1.26$, -0.538 , and 2.54 , resp.). Percentage error evaluation is helpful in establishing the validity of generated model equations to describe the domain of applicability of optimization model. The percentage error values reveal that mathematical models obtained from the full $3^{2}$ factorial designs were well fitted (Figure 4).

3.5. Bead Size. The average size of the formulated dried beads containing Lactobacillus sporogenes ranged from $1.15 \pm 0.03$ to $1.50 \pm 0.04 \mathrm{~mm}$.
TABLE 3: Results of experiments for confirming optimization capability.

(a)

\begin{tabular}{lccc}
\hline Code & Factor & \\
& $A(\%)$ & & $B(\%)$ \\
\hline F-O & 3.27 & 1.00 \\
\hline
\end{tabular}

(b)

\begin{tabular}{lccc}
\hline Response $^{\mathrm{a}}$ & $\begin{array}{c}\text { Predicted } \\
\text { value }\end{array}$ & $\begin{array}{c}\text { Observed } \\
\text { value }\end{array}$ & \% error \\
\hline $\begin{array}{l}Y_{1}=\text { entrapment } \\
\text { efficiency (\%) }\end{array}$ & 95.02 & $93.7 \pm 1.97$ & 1.39 \\
\hline $\begin{array}{l}Y_{2}=\text { viability in SGF after } \\
2 \mathrm{hr} \text { exposure (log CFU) }\end{array}$ & 9.3 & $9.34 \pm 0.3$ & -0.438 \\
\hline $\begin{array}{l}Y_{3}=\text { mucoadhesion over } \\
8 \mathrm{hr}(\%)\end{array}$ & 73.81 & $71.75 \pm 1.38$ & 3.60 \\
\hline
\end{tabular}

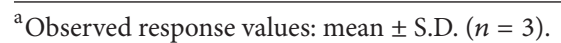

${ }^{\mathrm{b}}$ Error $(\%)=[$ difference between predicted value and actual value/predicted value] $\times 100$.

Increasing bead size was found with increasing amount of sodium alginate and sodium CMC. This could be attributed to increase in viscosity of the polymer blend (sodium alginate and sodium CMC) solution with incorporation of both the polymers in increasing ratio that in turn increased the droplet size during addition of the polymer blend solution to the cross-linking solution.

3.6. Surface Morphology Analysis. It can be inferred from the images that beads obtained were spherical in shape with smooth surfaces. The complete roughness of beads was 


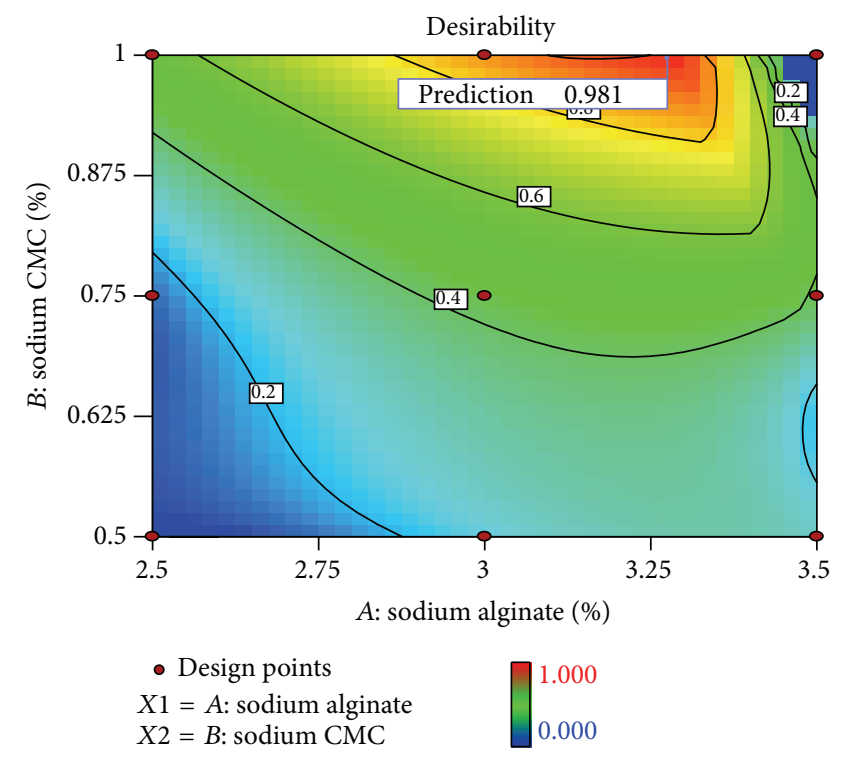

(a)

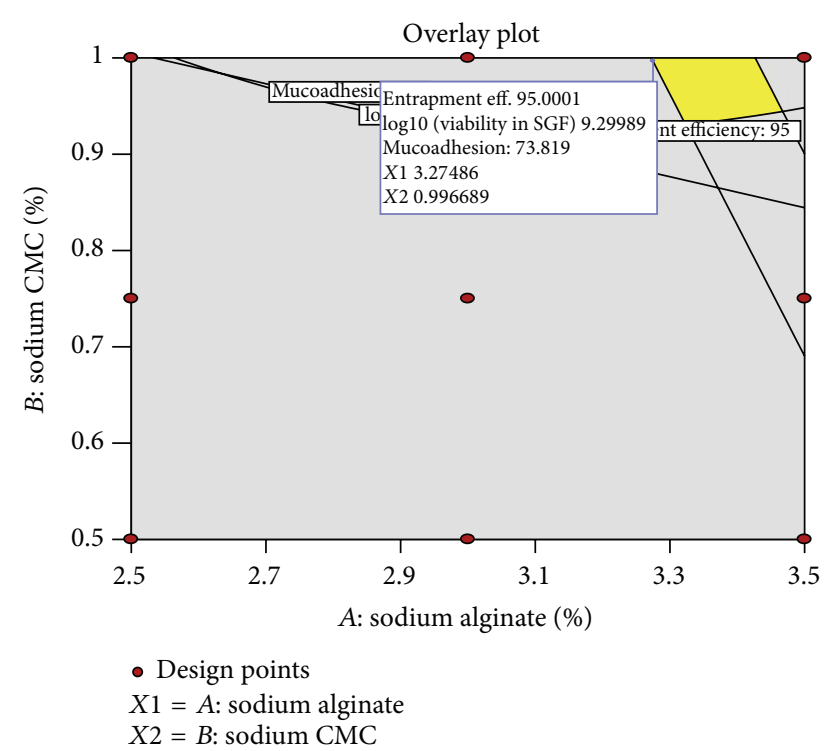

(b)

Figure 4: The desirability plot: (a) indicating desirable regression ranges and the overlay plot and (b) indicating the region of optimal process variable settings.

observed under higher magnification. Reduction of beads' size after dissolution was observed, so L. sporogenes might be released from the surface and gel matrix of sodium alginate. It might be due to erosion of beads during dissolution.

3.7. FTIR Spectroscopy. The FTIR spectra of probiotic $L$. sporogenes sodium alginate, sodium CMC, BioEcolian, and optimized ionotropically gelled sodium CMC-alginate beads containing L. sporogenes are shown in Figure 6.

In the FT-IR spectrum of sodium alginate powder, the various distinct peaks of alginate evident are those of the hydroxyl group at $3429 \mathrm{~cm}^{-1}$, carbonyl at $1614 \mathrm{~cm}^{-1}$, and carboxyl and carboxylate groups between 1000 and $1400 \mathrm{~cm}^{-1}$. The absorption band around 2880, 1656, 1421, and $1080 \mathrm{~cm}^{-1}$ corresponds to the stretching of - $\mathrm{CH}, \mathrm{COO}-,-\mathrm{CH}$, and C-O$\mathrm{C}$, respectively.

The IR spectra of sodium carboxy methyl cellulose exhibited presence of characteristic absorption bands corresponding to asymmetric and symmetric carboxylate anions at, respectively, $1609 \mathrm{~cm}^{-1}$ and $1426 \mathrm{~cm}^{-1}$, a broad band at $3412 \mathrm{~cm}^{-1}$ corresponding to stretching vibration of hydroxyl group, and a peak at $1059 \mathrm{~cm}^{-1}$ corresponding to alkyl substituted ether. The FTIR spectra of BioEcolian (GOS) showed characteristic peaks around $3500-3200 \mathrm{~cm}^{-1}$ for $\mathrm{OH}$ stretching, $2147 \mathrm{~cm}^{-1}$ for $\mathrm{CH}$ stretching, and $1650 \mathrm{~cm}^{-1}$ for CO stretching, $1025 \mathrm{~cm}^{-1}$.

In the FTIR spectrum of optimized ionotropically gelled sodium CMC-alginate beads containing L. sporogenes, various characteristic peaks of sodium alginate, sodium CMC, and $L$. sporogenes appeared without any significant shifting of these peaks. In short, the sodium CMC-alginate beads containing $L$. sporogenes prepared with sodium CMC-alginate polymer-blend had significant characters of $L$. sporogenes in the FTIR spectrum, suggesting absence of any interaction between the probiotic, L. sporogenes, and the polymer blend used.

3.8. X-Ray Diffraction Study. In order to confirm the physical state of the probiotic L. sporogenes in the beads, X-ray diffraction studies of the probiotic Lactobacillus sporogenes (a), L. sporogenes-containing beads (b) were carried out and the diffractograms shown in (Figures 7(a) and 7(b)). Lactobacillus sporogenes exhibited multiple characteristic sharp peaks at $2 \theta$ varying from $5^{\circ}$ to $50^{\circ}$ which were due to their crystalline nature. From the X-ray diffraction data of L. sporogenes-loaded beads, it was seen that no crystalline state of $L$. sporogenes was detected in L. sporogenes-loaded beads. This means that $L$. sporogenes was not present in the crystalline form in the bead matrix, but in an amorphous state. This clearly indicates that changes in the crystalline state of the L. sporogenes occurred during the preparation of beads by this ionotropic gelation method.

3.9. Swelling Behavior. The swelling index of ionotropically gelled optimized sodium alginate $\mathrm{CMC}$ beads containing L. sporogenes was found lower in $0.1 \mathrm{~N} \mathrm{HCl}, \mathrm{pH} 1.2$ in comparison with that of in phosphate buffer, $\mathrm{pH} 6.8$, initially. This occurred due to shrinkage of alginate at acidic $\mathrm{pH}$. Maximum swelling of these beads was noticed at $2-3 \mathrm{~h}$ in phosphate buffer, $\mathrm{pH} 6.8$, after which erosion and dissolution took place. It has been previously reported that the swelling of calcium alginate-based beads in presence of $\mathrm{Ca}^{2+}$ ioncapturing agent depends on the progressive displacement of $\mathrm{Ca}^{2+}$ ions within calcium alginate-based beads [21]. It has been also reported that the swelling enhanced of calcium alginate-based beads by the presence of phosphate ions 

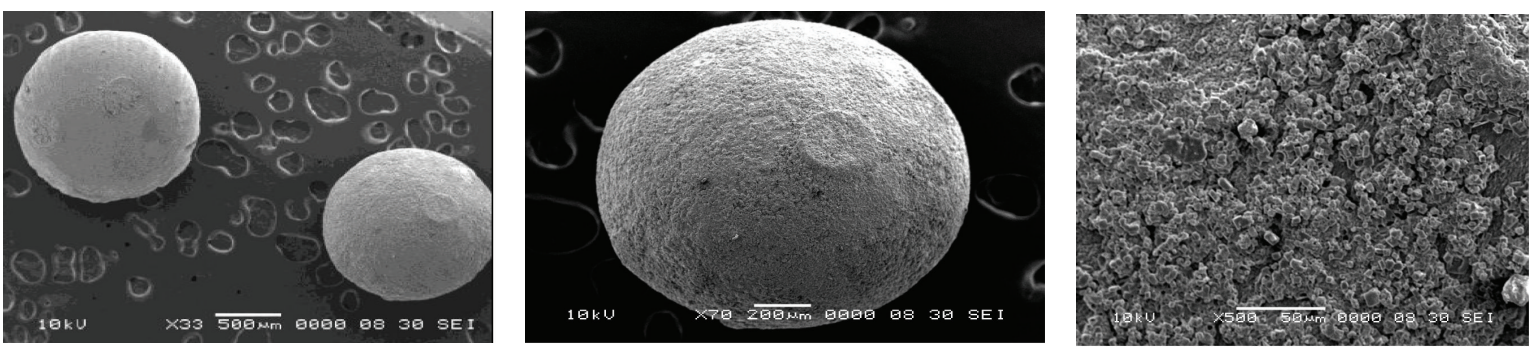

(a) Lactobacillus sporogenes-loaded beads batch F-O
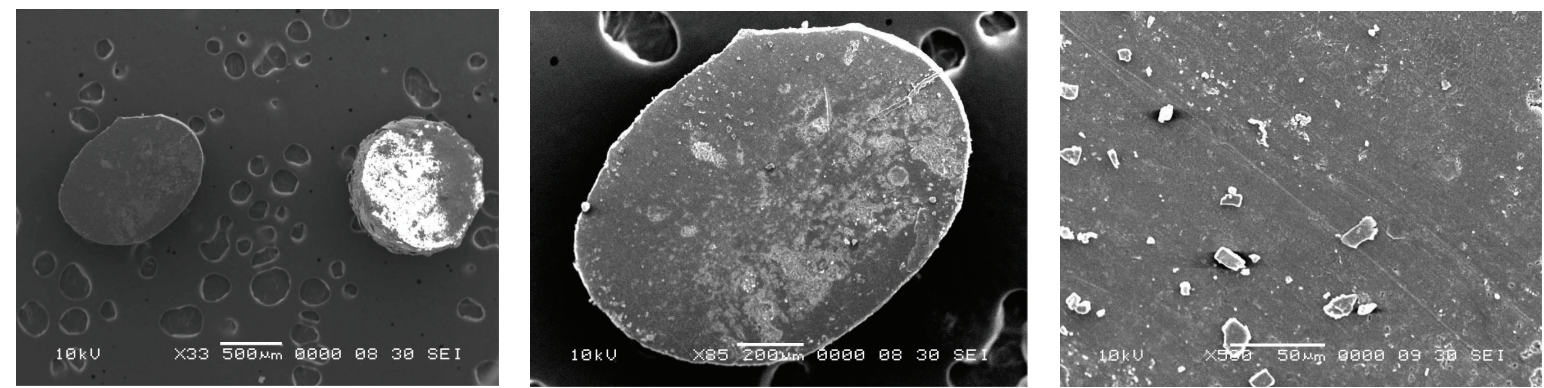

(b) Cross section of Lactobacillus sporogenes-loaded optimized batch
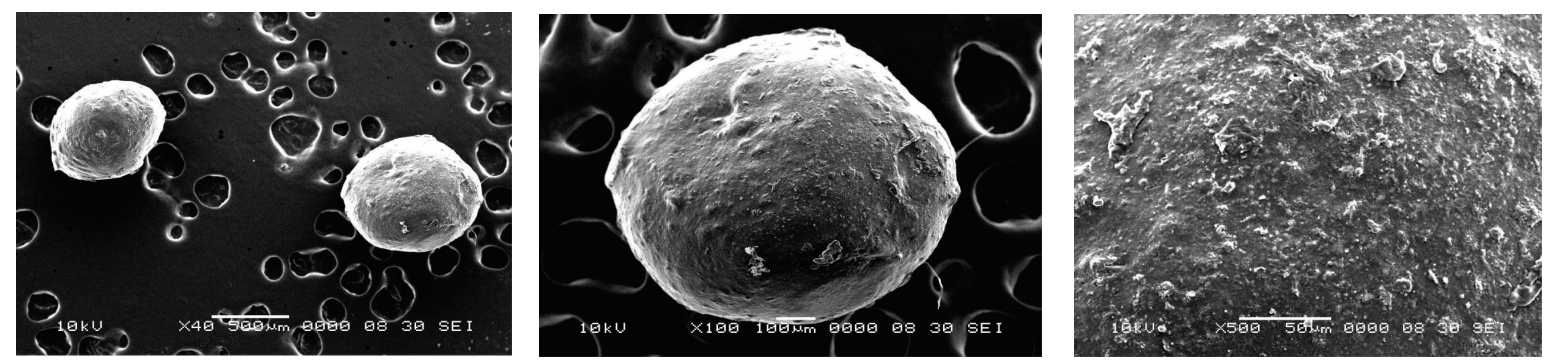

(c) After dissolution of optimized batch
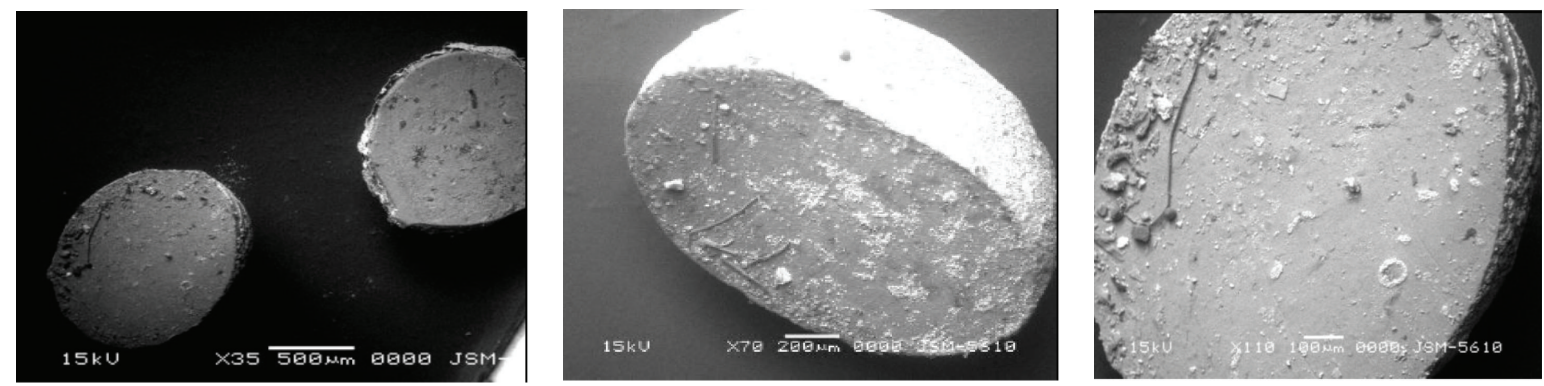

(d) Cross section of after dissolution Lactobacillus sporogenes optimized batch

FIGURE 5: Depicts the scanning electron microscopy (SEM) images of dried beads of Lactobacillus sporogenes at different magnification, (a) Lactobacillus sporogenes-loaded batch D9, (b) cross section Of Lactobacillus sporogenes-loaded batch D9, (c) after dissolution of Lactobacillus sporogenes-loaded batch D9, and (d) cross section of after dissolution Lactobacillus sporogenes-loaded batch (D9).

(in phosphate buffer), which act as $\mathrm{Ca}^{2+}$ sequestrant [34]. Therefore, the swelling behaviour of these beads containing $L$. sporogenes in phosphate buffer, $\mathrm{pH} 6.8$, could be explained by the ion exchanging between $\mathrm{Ca}^{2+}$ ions of the ionotropically cross-linked beads and the $\mathrm{Na}^{+}$ions present in phosphate buffer with the influence of $\mathrm{Ca}^{2+}$ sequestrant phosphate ions. This could result in disaggregation in the sodium alginate CMC matrix structure leading to matrix erosion and dissolution of the swollen beads. This phenomenon clearly suggests that the ionotropically gelled optimized sodium alginate CMC beads containing $L$. sporogenes are able to swell slightly in the stomach and begin to swell more when these beads subsequently move to the upper intestine, where the $L$. sporogenes is to be absorbed.

3.10. Stability Study of Free and Encapsulated L. sporogenes. The final challenge related to the development of probioticloaded microcapsules was represented by their stability 
TABLE 4: Mean diameter of calcium alginate/CMC beads containing L. sporogenes.

\begin{tabular}{lc}
\hline Formulation code & Mean diameter $(\mathrm{mm})^{\mathrm{a}}$ \\
\hline D1 & $1.15 \pm 0.03$ \\
D2 & $1.3 \pm 0.04$ \\
D3 & $1.39 \pm 0.03$ \\
D4 & $1.17 \pm 0.07$ \\
D5 & $1.22 \pm 0.04$ \\
D6 & $1.41 \pm 0.02$ \\
D7 & $1.19 \pm 0.04$ \\
D8 & $1.24 \pm 0.02$ \\
D9 & $1.50 \pm 0.04$
\end{tabular}

${ }^{\mathrm{a}}$ mean $\pm \mathrm{SD}$.

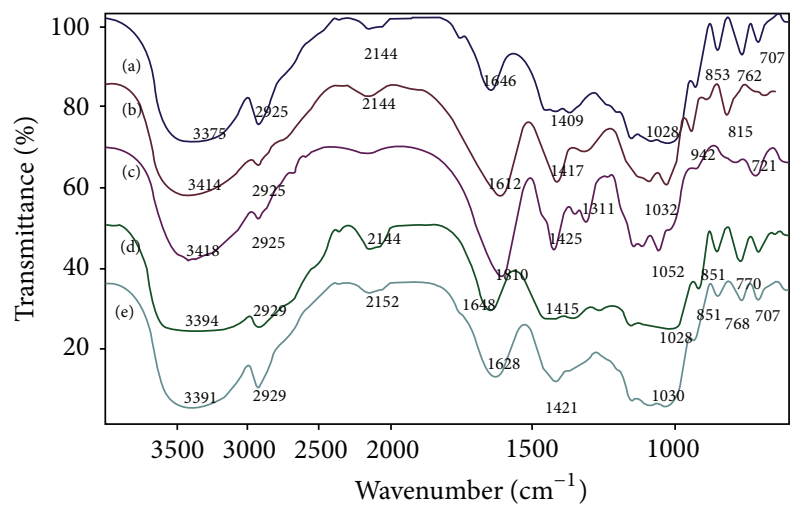

FIgURE 6: The FTIR spectra of L. sporogenes (a), sodium alginate (b), sodium CMC (c), BioEcolian (d), and sodium alginate sodium CMC beads containing L. sporogenes (F-O) (e).

during storage. When probiotics are exposed to moisture, oxygen, and heat, irreversible damage to microbial cells occurs. The stability of probiotics is particularly important for the pharmaceutical products, as they are often stored for longer periods than the dairy products [35]. Products in powder form, even capsules or tablets, generally have displayed longer stability than the liquid preparations when stored at low temperature, showing a tendency to decrease the viable count throughout the storage period. Actually, the data reported in literature $[36,37]$ evidence a decrease in survival of probiotic strains when stored for up to 6 months at room temperature or in the refrigerator. Anyway the decrease of the viability of the samples stored in the refrigerator is significantly lower than that of products stored at room temperature. In this research stability of probiotics bacteria in FDP and formulated in microcapsules during storage, room temperature $\left(24-28^{\circ} \mathrm{C}\right)$ was investigated over 2 months (Figure 9). There was not much variation in beads at these temperature conditions. There were no significant changes in entrapment efficiency, physical stability, and survival of encapsulated L. sporogenes for the selected optimized formulation F-O after 30 days and 60 days at room temperature (24$28^{\circ} \mathrm{C}$ ). The results of stability study after two months are given in Table 5.

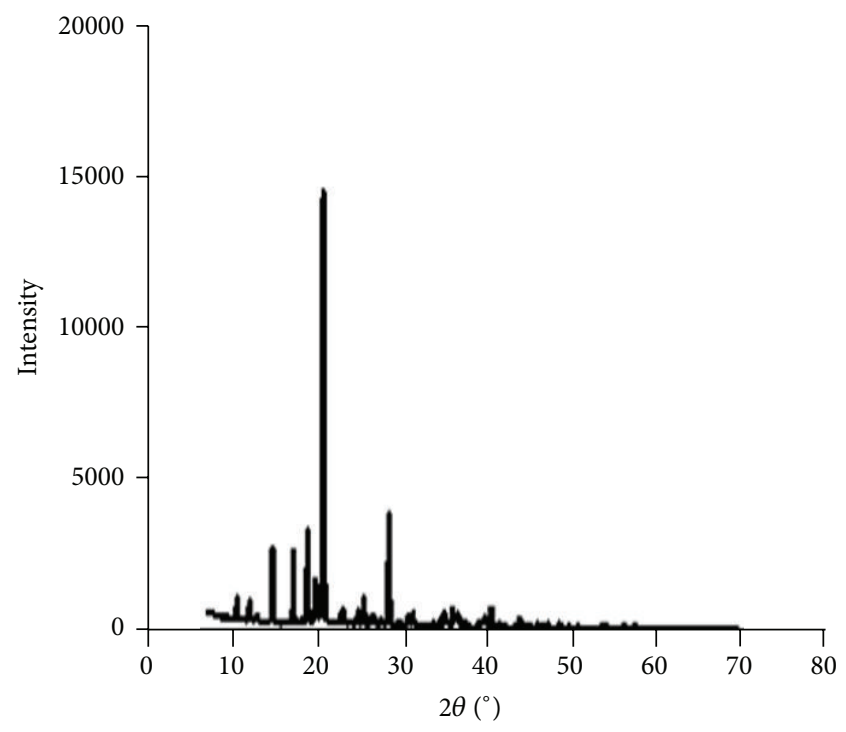

(a)

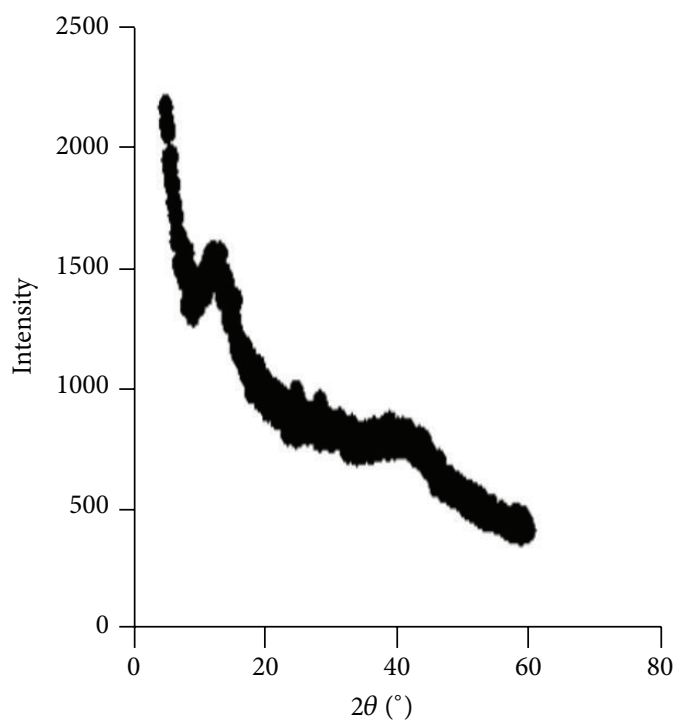

(b)

FIGURE 7: XRD spectra of (a) L. sporogenes and (b) L. sporogenesloaded beads.

The cell survival after 30 days was 6.88 and 7.85 of the initial $\log \mathrm{CFU}$ in free and encapsulated L. sporogenes, respectively. The viability of $L$. sporogenes free cells showed a decrease to $5.36 \log$ CFU after 60 days, throughout the storage period at room temperature $\left(24-28^{\circ} \mathrm{C}\right)$, whereas viability for alginate encapsulated $L$. sporogenes beads showed little decrease to 7.41 after 60 days throughout the storage period at room temperature $\left(24-28^{\circ} \mathrm{C}\right)$.

\section{Conclusion}

In this investigation, ionotropically gelled carboxymethylcellulose (CMC) Ca-alginate mucoadhesive beads containing $L$. sporogenes were successfully developed and optimized using $3^{2}$ factorial designs. The primary response, viability of the 
TABLE 5: Results for stability study.

\begin{tabular}{lcccc}
\hline Time in days & Shape of beads & \% probiotic entrapment efficiency & \multicolumn{2}{c}{$\begin{array}{c}\text { Survival of L. sporogenes (log CFU/g) } \\
\text { Encapsulated L. sporogenes beads }\end{array}$} \\
\cline { 4 - 5 } Initial & Round & $93.59 \pm 0.4$ & $8.68 \pm 0.32$ & $8.59 \pm 0.24$ \\
After 30 days & Round & $92.5 \pm 0.5$ & $6.88 \pm 0.30$ & $7.85 \pm 0.23$ \\
After 60 days & Round & $92.09 \pm 0.2$ & $5.36 \pm 0.24$ & $7.41 \pm 0.37$ \\
\hline
\end{tabular}
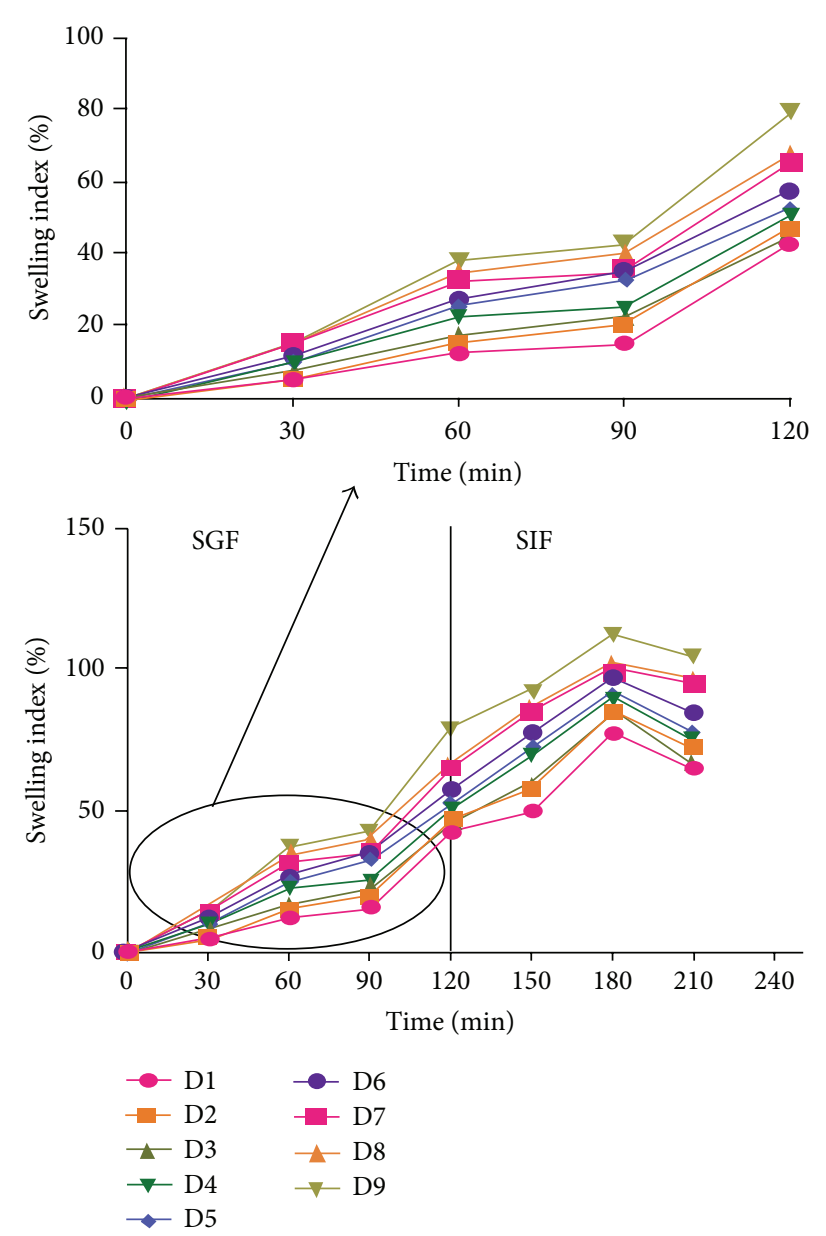

FIGURE 8: Swelling behaviour of optimized sodium CMC-alginate beads containing L. sporogenes in $0.1 \mathrm{~N} \mathrm{HCl}(\mathrm{pH} 1.2)$, and phosphate buffer ( $\mathrm{pH}$ 7.4) [mean \pm S.D., $n=3]$.

encapsulated L. sporogenes in simulated gastric conditions, pointed to the formulation factor with the lowest influence, that is, sodium alginate and sodium CMC. In this respect and in conjunction with the other experimental responses as well, it was concluded that the optimal formulation of $L$. sporogenes-loaded carboxymethylcellulose-Ca-alginate microparticles should be prepared using 3.27\% w/v sodium alginate, $1.00 \% \mathrm{w} / \mathrm{v}$ sodium $\mathrm{CMC}$, and $5 \% \mathrm{w} / \mathrm{v} \mathrm{CaCl}_{2}$. The optimized beads demonstrated goodp entrapment efficiency, good mucoadhesivity with the biological membrane, and suitable controlled probiotic release pattern over prolonged period, which could possibly be advantageous in terms of advanced patient compliance with reduced dosing interval.

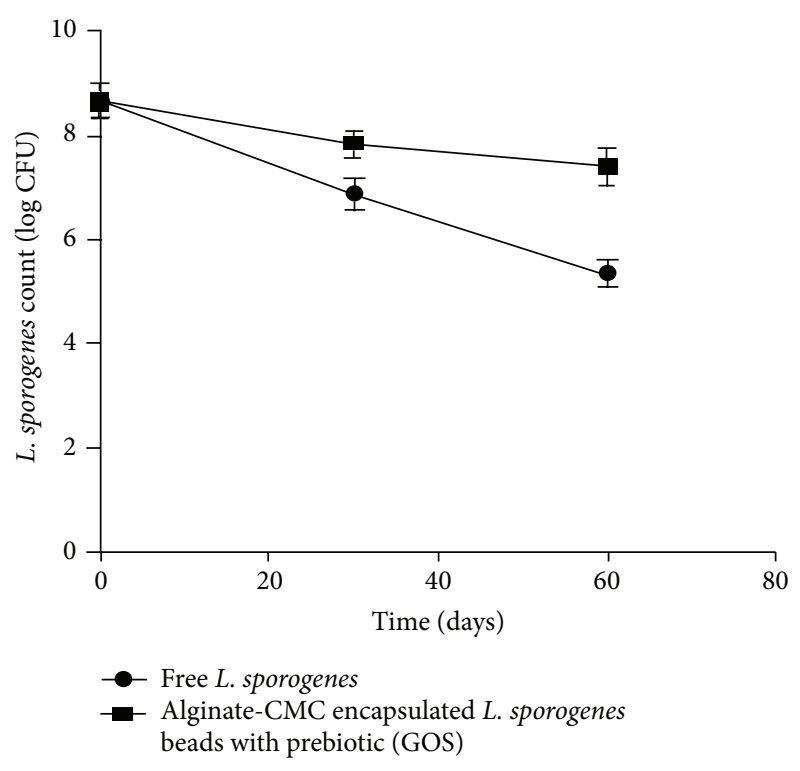

FIGURE 9: Shows the stability of free and encapsulated L. sporogenes during 60 days of storage at room temperature $\left(24-28^{\circ} \mathrm{C}\right)$.

The technique for the preparation of CMC-calcium alginate beads containing $L$. sporogenes was found to be simple, reproducible, easily controllable, economical, and consistent. Besides, the excipients such as sodium alginate, sodium $\mathrm{CMC}$, and calcium chloride used for the formulation of these beads were cheap and easily available.

\section{Conflict of Interests}

The authors declare no conflict of interests.

\section{Acknowledgments}

The valuable help of Unique Biotech Limited, Unit-II, Hyderabad, India, for the identification of probiotic L. sporogenes is gratefully acknowledged. The authors are very grateful to Dr. Girish K. Jani, Principal, and Mr. Vipul D. Prajapati, Associate Professor, SSR College of Pharmacy, Silvassa, DNH, India, for their assistance. The authors are very thankful to Mr. Deepak Pawar for his help in statistical analysis of data.

\section{References}

[1] W. P. Charteris, P. M. Kelly, L. Morelli, and J. K. Collins, "Development and application of an in vitro methodology to determine the transit tolerance of potentially probiotic 
Lactobacillus and Bifidobacterium species in the upper human gastrointestinal tract," Journal of Applied Microbiology, vol. 84, no. 5, pp. 759-768, 1998.

[2] S. Rokka and P. Rantamäki, "Protecting probiotic bacteria by microencapsulation: challenges for industrial applications," European Food Research and Technology, vol. 231, no. 1, pp. 1-12, 2010.

[3] M. De Vrese and P. R. Marteau, "Probiotics and prebiotics: effects on diarrhea," Journal of Nutrition, vol. 137, no. 3, pp. 803S811S, 2007.

[4] Y. Doleyres and C. Lacroix, "Technologies with free and immobilised cells for probiotic bifidobacteria production and protection," International Dairy Journal, vol. 15, no. 10, pp. 973988, 2005.

[5] A. Lopez-Rubio, R. Gavara, and J. M. Lagaron, "Bioactive packaging: turning foods into healthier foods through biomaterials," Trends in Food Science and Technology, vol. 17, no. 10, pp. 567$575,2006$.

[6] G. R. Gibson, "From probiotics to prebiotics and a healthy digestive system," Journal of Food Science, vol. 69, no. 5, pp. M141-M143, 2004.

[7] L. J. Fooks, R. Fuller, and G. R. Gibson, "Prebiotics, probiotics and human gut microbiology," International Dairy Journal, vol. 9, no. 1, pp. 53-61, 1999.

[8] R. A. Rastall and V. Maitin, "Prebiotics and synbiotics: towards the next generation," Current Opinion in Biotechnology, vol. 13, no. 5, pp. 490-496, 2002.

[9] E. E. Vaughan, H. G. H. J. Heilig, K. Ben-Amor, and W. M. de Vos, "Diversity, vitality and activities of intestinal lactic acid bacteria and bifidobacteria assessed by molecular approaches," FEMS Microbiology Reviews, vol. 29, no. 3, pp. 477-490, 2005.

[10] A. K. Anal and H. Singh, "Recent advances in microencapsulation of probiotics for industrial applications and targeted delivery," Trends in Food Science and Technology, vol. 18, no. 5, pp. 240-251, 2007.

[11] T. Heidebach, P. Först, and U. Kulozik, "Microencapsulation of probiotic cells for food applications," Critical Reviews in Food Science and Nutrition, vol. 52, no. 4, pp. 291-311, 2012.

[12] C. P. Champagne and P. Fustier, "Microencapsulation for the improved delivery of bioactive compounds into foods," Current Opinion in Biotechnology, vol. 18, no. 2, pp. 184-190, 2007.

[13] W. Krasaekoopt, B. Bhandari, and H. Deeth, "Evaluation of encapsulation techniques of probiotics for yoghurt," International Dairy Journal, vol. 13, no. 1, pp. 3-13, 2003.

[14] W. Krasaekoopt, B. Bhandari, and H. Deeth, "The influence of coating materials on some properties of alginate beads and survivability of microencapsulated probiotic bacteria," International Dairy Journal, vol. 14, no. 8, pp. 737-743, 2004.

[15] Y. L. Patel, P. Sher, and A. P. Pawar, "The effect of drug concentration and curing time on processing and properties of calcium alginate beads containing metronidazole by response surface methodology," AAPS PharmSciTech, vol. 7, no. 4, article 86, 2006.

[16] F. Llanes, D. H. Ryan, and R. H. Marchessault, "Magnetic nanostructured composites using alginates of different $M / G$ ratios as polymeric matrix," International Journal of Biological Macromolecules, vol. 27, no. 1, pp. 35-40, 2000.

[17] Y. Rane, R. Mashru, M. Sankalia, and J. Sankalia, "Effect of hydrophilic swellable polymers on dissolution enhancement of carbamazepine solid dispersions studied using response surface methodology," AAPS PharmSciTech, vol. 8, no. 2, pp. E1-E11, 2007.
[18] S. K. Prajapati, P. Tripathi, U. Ubaidulla, and V. Anand, "Design and development of gliclazide mucoadhesive microcapsules: in vitro and In vivo evaluation," AAPS PharmSciTech, vol. 9, no. 1, pp. 224-230, 2008.

[19] F. Lotfipour, S. Mirzaeei, and M. Maghsoodi, "Preparation and characterization of alginate and psyllium beads containing Lactobacillus acidophilus," The Scientific World Journal, vol. 2012, Article ID 680108, 8 pages, 2012.

[20] M. S. Khan, B. K. Sridhar, and A. Srinatha, "Development and evaluation of $\mathrm{pH}$-dependent micro beads for colon targeting," Indian Journal of Pharmaceutical Sciences, vol. 72, no. 1, pp. 1823, 2010.

[21] V. K. Sharma and A. Bhattacharya, "Release of metformin hydrochloride from Ispaghula-sodium alginate beads adhered on cock intestinal mucosa," Indian Journal of Pharmaceutical Education and Research, vol. 42, no. 4, pp. 363-370, 2008.

[22] J. B. Schwartz, R. E. O'conor, and R. L. Schnaare, "Optimization technique in pharmaceutical formulation and processing," in Modern Pharmaceutics, G. S. Banker and C. T. Rhodes, Eds., pp. 607-627, Marcel Dekker, New York, NY, USA, 4th edition, 2007.

[23] A. Hooda, A. Nanda, M. Jain, V. Kumar, and P. Rathee, "Optimization and evaluation of gastroretentive ranitidine $\mathrm{HCl}$ microspheres by using design expert software," International Journal of Biological Macromolecules, vol. 51, no. 5, pp. 691-700, 2012.

[24] J. Singh, A. K. Philip, and K. Pathak, "Optimization studies on design and evaluation of orodispersible pediatric formulation of indomethacin," AAPS PharmSciTech, vol. 9, no. 1, pp. 60-66, 2008.

[25] A. K. Nayak, B. Das, and R. Maji, "Calcium alginate/gum arabic beads containing glibenclamide: development and in vitro characterization," International Journal of Biological Macromolecules, vol. 51, no. 5, pp. 1070-1078, 2012.

[26] J. Malakar, A. K. Nayak, and D. Pal, "Development of cloxacillin loaded multiple-unit alginate-based floating system by emulsion-gelation method," International Journal of Biological Macromolecules, vol. 50, no. 1, pp. 138-147, 2012.

[27] B. Singh, R. Kapil, M. Nandi, and N. Ahuja, "Developing oral drug delivery systems using formulation by design: vital precepts, retrospect and prospects," Expert Opinion on Drug Delivery, vol. 8, no. 10, pp. 1341-1360, 2011.

[28] V. Chandramouli, K. Kailasapathy, P. Peiris, and M. Jones, "An improved method of microencapsulation and its evaluation to protect Lactobacillus spp. in simulated gastric conditions," Journal of Microbiological Methods, vol. 56, no. 1, pp. 27-35, 2004.

[29] C. Iyer and K. Kailasapathy, "Effect of co-encapsulation of probiotics with prebiotics on increasing the viability of encapsulated bacteria in simulated gastrointestinal conditions and in yoghurt," Journal of Food Science, vol. 70, no. 1, pp. M18-M23, 2005.

[30] W. K. Ding and N. P. Shah, "Effect of various encapsulating materials on the stability of probiotic bacteria," Journal of Food Science, vol. 74, no. 2, pp. M100-M107, 2009.

[31] K.-Y. Lee and T.-R. Heo, "Survival of Bifidobacterium longum immobilized in calcium alginate beads in simulated gastric juices and bile salt solution," Applied and Environmental Microbiology, vol. 66, no. 2, pp. 869-873, 2000.

[32] K. Sultana, G. Godward, N. Reynolds, R. Arumugaswamy, P. Peiris, and K. Kailasapathy, "Encapsulation of probiotic bacteria 
with alginate-starch and evaluation of survival in simulated gastrointestinal conditions and in yoghurt," International Journal of Food Microbiology, vol. 62, no. 1-2, pp. 47-55, 2000.

[33] L. T. Hansen, P. M. Allan-Wojtas, Y.-L. Jin, and A. T. Paulson, "Survival of Ca-alginate microencapsulated Bifidobacterium spp. in milk and simulated gastrointestinal conditions," Food Microbiology, vol. 19, no. 1, pp. 35-45, 2002.

[34] R. S. Al-Kassas, O. M. N. Al-Gohary, and M. M. Al-Faadhel, "Controlling of systemic absorption of gliclazide through incorporation into alginate beads," International Journal of Pharmaceutics, vol. 341, no. 1-2, pp. 230-237, 2007.

[35] J.-H. Cui, J.-S. Goh, P.-H. Kim, S.-H. Choi, and B.-J. Lee, "Survival and stability of bifidobacteria loaded in alginate poly1-lysine microparticles," International Journal of Pharmaceutics, vol. 210, no. 1-2, pp. 51-59, 2000.

[36] M. I. Brachkova, A. Duarte, and J. F. Pinto, "Evaluation of the viability of Lactobacillus spp. after the production of different solid dosage forms," Journal of Pharmaceutical Sciences, vol. 98, no. 9, pp. 3329-3339, 2009.

[37] S. Klayraung, H. Viernstein, and S. Okonogi, "Development of tablets containing probiotics: effects of formulation and processing parameters on bacterial viability," International Journal of Pharmaceutics, vol. 370, no. 1-2, pp. 54-60, 2009. 

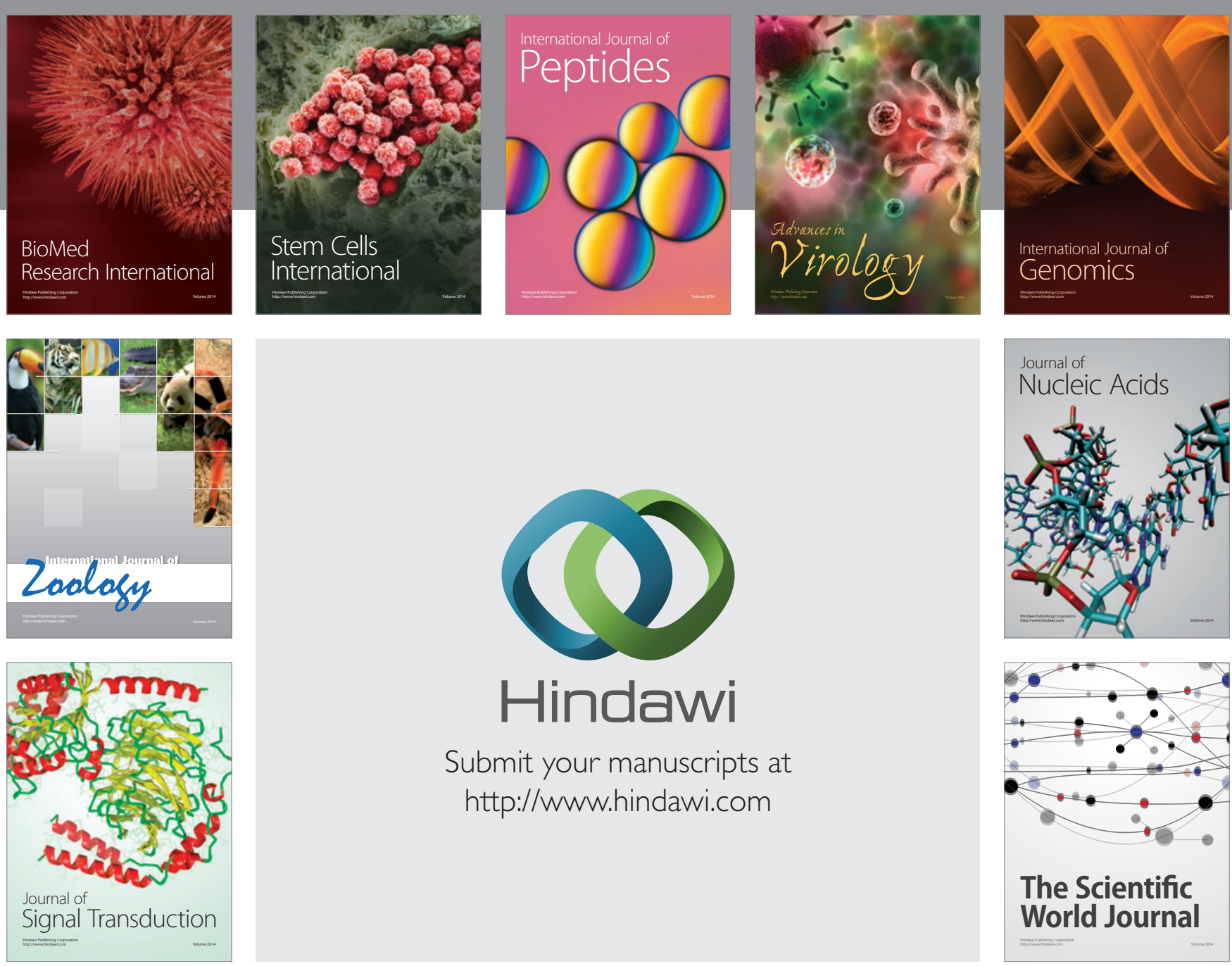

Submit your manuscripts at

http://www.hindawi.com
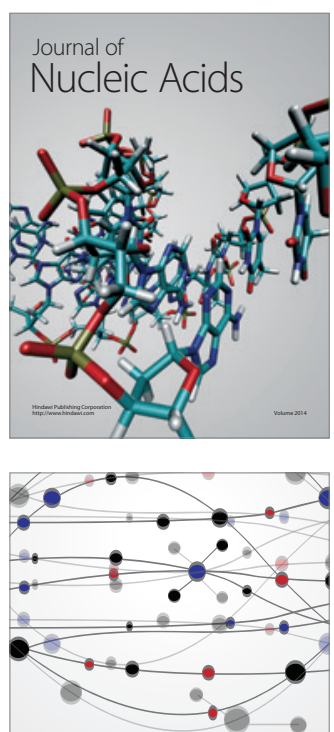

The Scientific World Journal
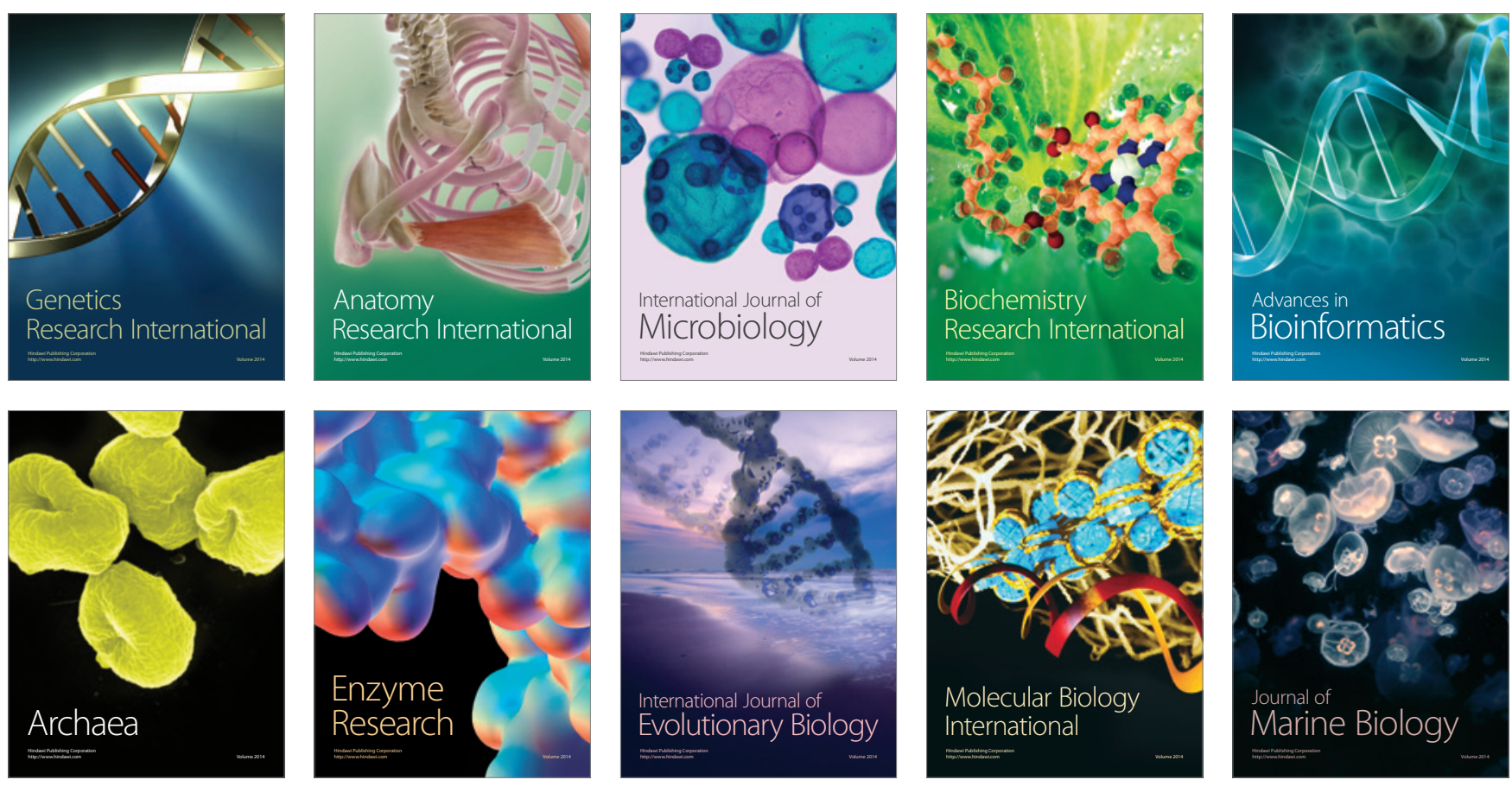